\title{
Research of Kinetic Impregnation Process Based on the Structure of Reinforcing Filler
}

\author{
Phone Thant $\mathrm{Kyaw}^{1,}{ }^{*}$, Pyae Phyo Maung ${ }^{1}$, and G.V. Malysheva ${ }^{1}$ \\ ${ }^{1}$ Bauman Moscow State Technical University (BMSTU), Moscow, 105005, Moscow, 5, 2nd \\ Baumanskaya Str.,Russia
}

\begin{abstract}
The present work studies the impregnation process through a carbon-fiber-reinforced plastic (CFRP) during the resin injection filling stage of a vacuum infusion process by using simulation software PAMRTM. Our work aims to study the resin injection time of carbon fabric composite laminate based on the type of weaving fabrics, permeability and porosity of reinforced fabric and to define the optimal structure of reinforced fabric based on simulation and experimental results. The resin infusion method procured from simulation and experimental results can effectively avoid the high cost caused by the trial-and-error method.
\end{abstract}

\section{Introduction}

Composite Materials are becoming more popular gradually replacing traditional materials with extra strength, lighter weight, and thermal properties [1-14]. Many composites' industries are exploring the use of fiber-reinforced composites in all applications which includes aerospace, automotive and water transport, construction industry, toys, instrumentation, medicine, etc. Based on application and reinforcement used, there are many ways to manufactures parts with fiber-reinforced composites. Various techniques are available depending on the type of reinforcement used and the application of the product. If we compare different manufacturing processes, most of the polymer composite products are made with vacuum infusion technology because of the huge potential to manufacture critical parts with required properties at an economical rate. Various types of resin infusion processing have emerged as popular manufacturing options due to their relatively low costper-properties ratio.

In our work, the resin impregnation process of composite materials based on carbonfiber-reinforced plastic (CFRP) made it possible to simultaneously provide strength and lightweight construction. For the production technology vacuum assisted resin infusion (VARI) process is used. This process is a very attractive composite manufacturing process since large structures can be fabricated cost-effectively.

The quality and properties of manufactured parts with this impregnation process are influenced by several parameters. In our case, the influence of structure of the reinforced fabric on the duration of the impregnation process by vacuum infusion process was studied. The mechanical properties of the resulting composite in the load direction depend on the

\footnotetext{
* Corresponding author: phonethantkyaw92@gmail.com
} 
structure of reinforced fabric. Regarding the resin injection process, the structure of reinforcing fillers affects directly the filling time, and the successful and complete impregnation of the final product by the resin.

The prediction of flow behavior during the filling mold stage is critical to obtain a highquality product and develop an efficient process with sufficient filling strategies to avoid dry areas and decrease the mold filling time. To carry out accurate simulation, knowledge of several experimental parameters such as type of weaving, the resin properties, and the porosity and permeability values of the fiber materials are required. Therefore, in our study to simulate the impregnation technology, the PAM-RTM software is used, which allows us to determine the duration of the impregnation process.

\section{Methodology}

The object of our work consists of four main stages. The first part of our work is analysing the structures of fabric weaving and properties of epoxy resin. Secondly, creating the 3D geometry of fabric weaving structure in the program Digimat and analytical calculation of porosity for different types of fabric weaving. Thirdly, the numerical modelling of the VARI process in PAM-RTM software implies the modelling of the resin infusion time based on the different values of permeability and finally optimized the permeability of reinforced fabric and the structure of fabric weaving based on the minimum resin infusion time.

The model of our study is a composite plate made of carbon fiber reinforced plastics. For the production of the sample, different types of carbon fabrics were used as reinforced materials and the epoxy resin (EDT-10) was used as a binding material (Table 1).

Table 1. Mechanical properties of epoxy resin

\begin{tabular}{|c|c|c|}
\hline Epoxy resin & Density $\left(\mathrm{kg} / \mathrm{m}^{3}\right)$ & Viscosity $\left(\mathrm{Pa}^{*} \mathrm{~s}\right)$ \\
\hline EDT-10 & 1500 & 1,5 \\
\hline
\end{tabular}

The choice of this material was associated with its good rheological properties, good physical-mechanical properties and low cost. In our work, fabrics of plain, twill (2/1) and satin (3/1) weaving patterns were selected. Physical-mechanical properties (Table 2) of carbon fabric are shown in following.

Table 2. Physical-mechanical properties of carbon fabrics

\begin{tabular}{|c|c|c|c|}
\hline & Plain & Twill $(2 / 1)$ & Satin (3/1) \\
\hline Density $\left(\mathrm{kg} / \mathrm{m}^{3}\right)$ & 1800 & 1800 & 1800 \\
\hline $\begin{array}{c}\text { Yarn linear density } \\
(\text { Tex })\end{array}$ & 1800 & 1800 & 1800 \\
\hline Fiber diameter $(\mathrm{mm})$ & 0.009 & 0.009 & 0.009 \\
\hline $\begin{array}{c}\text { Yarn cross-section, } \\
\mathrm{h} \times \mathrm{W}(\mathrm{mm})\end{array}$ & $0.1 \times 1$ & $0.1 \times 1$ & $0.1 \times 1$ \\
\hline Fiber thickness & 0.1 & 0.1 & 0.1 \\
\hline $\begin{array}{c}\text { Fabric size, } 1 \times \mathrm{w} \times \mathrm{h} \\
(\mathrm{mm})\end{array}$ & $300 \times 150 \times 0.2$ & $300 \times 150 \times 0.2$ & $300 \times 150 \times 0.2$ \\
\hline Warp yarn count & 10 & 10 & 10 \\
\hline Weft yarn count & 5 & 5 & 0 \\
\hline Yarn spacing ratio & 0 & 0 & \\
\hline
\end{tabular}

One of the most critical factors in setting the boundary conditions of the numerical model is the knowledge of permeability values and porosity of the reinforcing materials, because it influence on the resin flow behaviour during resin injection process. The 
permeability characterizes the relative facility of a viscous liquid to impregnate a porous medium. This physical property of the porous medium depends on the fiber volume fraction and on the draping of the plies.

\section{Modeling and simulation calculations}

The geometry of carbon fiber reinforced plastic model is modeled using FEM software MSC-Digimat (Fig. 1). The first one is plain weaning, max porosity is 0,4 and second one is twill fabric with the porosity of 0,42 , the third one is satin weaing with porosity of 0,48 . By using the fabric simulation software and analytical calculation, we can see the difference porosity values (Table 3 ).In this paper, we will focus on plate made from fabrics. Fabrics are characterized by two different length scales: the scale of the length of one thread (for example, its radius) and the scale of the length of the bundle of threads. Consequently, fabrics also have a dual characteristic of porosity. The first defined porosity is associated with the internal structure of the filament and is called here the "porosity of the filament". The second porosity is caused by voids between the filaments and is called here the "interlacing porosity". To calculate the porosity of the weave, the threads are assumed to be solid (zero filament porosity); then the weaving porosity is defined as the ratio of the volume of voids between the threads to the total volume of the minimum limiting frame of the fabric (in this study, the unit cell).

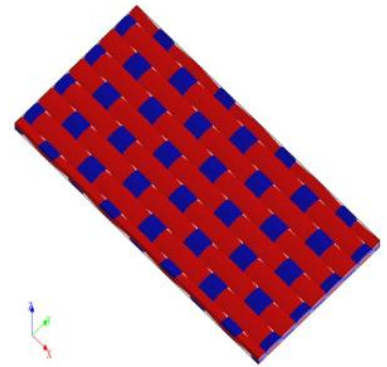

(a)

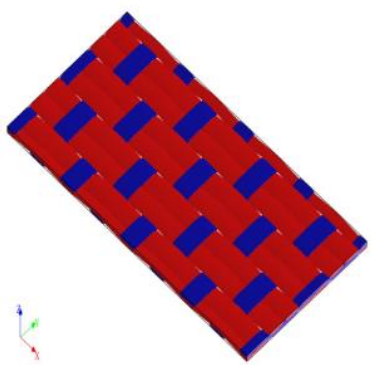

(b)

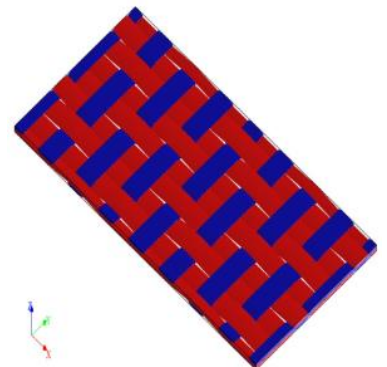

(c)

Fig. 1. 3D geometry in MSC-Digimat: a) Plain weave; b) Twill weave (2/1); c) Satin weave (3/1)

Table 3. Porosity results of modelling and analytical calculations

\begin{tabular}{|l|c|c|c|}
\hline & & & \\
\hline & Plain weave & Twill weave & Satin weave \\
\hline Unit cell size $(\mathrm{mm})$ & $16 \times 8 \times 0.2$ & $30 \times 15 \times 0.2$ & $50 \times 12.5 \times 0.2$ \\
\hline $\begin{array}{l}\text { Areal Density }(\text { dry }), \\
(\mathrm{g} / \mathrm{m} 2)\end{array}$ & 2708.6 & 540.036 & 900.076 \\
\hline Fiber volume fraction & 0.53 & 0.49 & 0.42 \\
\hline Porosity (inter-yarn) & 0.4 & 0.42 & 0.48 \\
\hline
\end{tabular}

The created 3D composite plate geometry is transformed Visual Mesh for meshing (Fig. 2). In the process of meshing geometry, type of mesh element is tria and size of the element is $1 \mathrm{~mm}$. The fabric model is meshed into 324348 elements. After creating the mesh model, the mesh model is exported to the program PAM-RTM for modeling of resin impregnation process. 


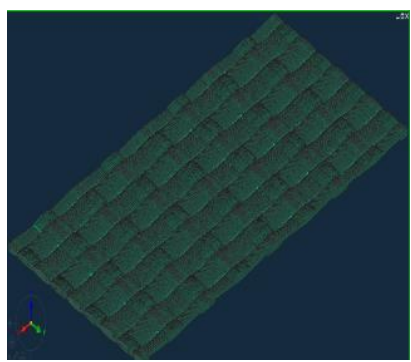

(a)

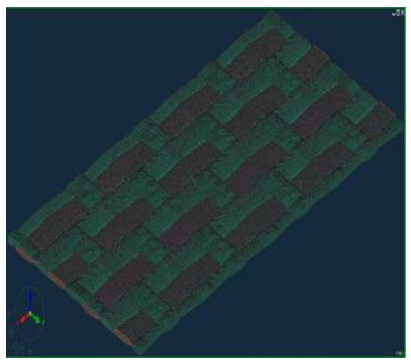

(b)

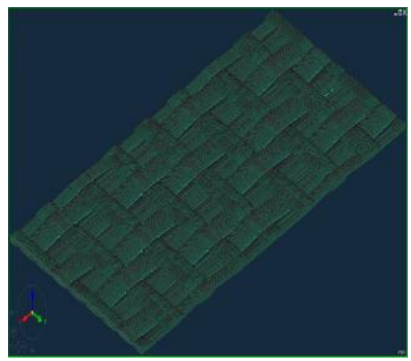

(c)

Fig. 2. Mesh model of composite plate in the program Visual-Mesh: a) Plain weave; b) Twill weave $(2 / 1)$; c) Satin weave $(3 / 1)$

To calculate the resin impregnation process in the program PAM-RTM, simulation type, resin properties, fabric properties, laminates properties were set (Fig 3). Boundary conditions of the VARI process for composite plate are implied as the (Fig 4). The inlet gate and outlet vent pressures are one atmosphere and vacuum pressure, respectively.

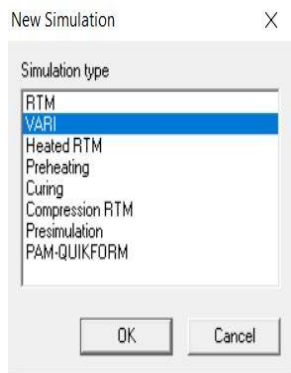

(a)

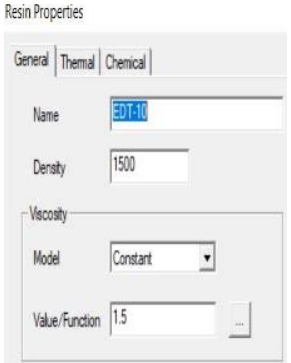

(b)

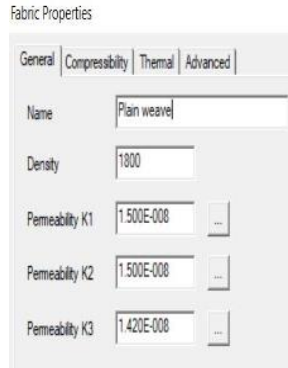

(c)

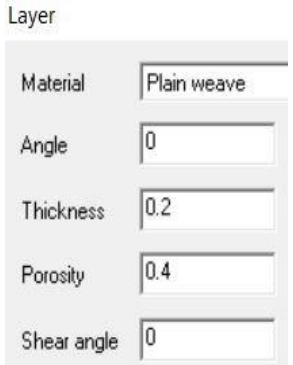

(d)

Fig. 3. Setting parameters for VARI process in the program PAM-RTM: a) Simulation type; b) Resin properties; c) Fabric properties; d) Layer properties

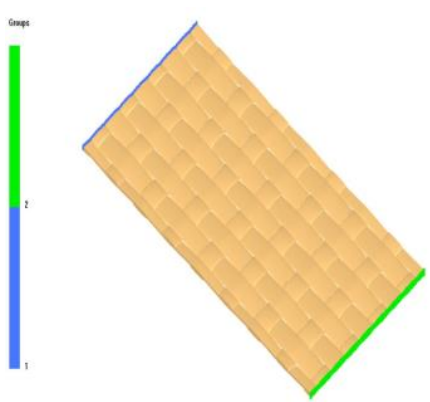

(a)

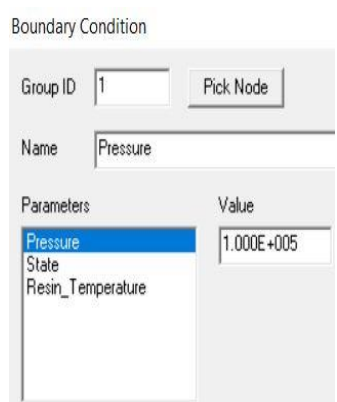

(b)

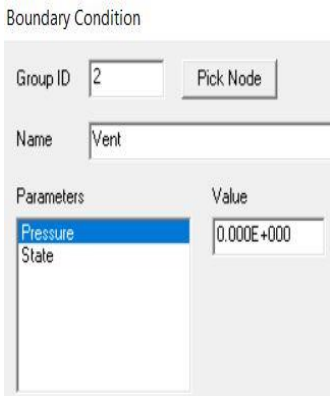

(c)

Fig. 4. Bountry condition of composite plate in the program PAM-RTM : a) Groups; b) Pressure; c) Vent

The optimization of the structure of reinforced fabric based on coefficient of permeability was calculated in the PAM-RTM program for three different reinforced fabrics and three different coefficient of permeability. The porosity of the same fabric weaving was considered as the same. In the same fabric type, varying the permeability of the reinforced fabric and optimized the reinforced fabric with the minium resin 
impregnation time. In the different fabric types, varying the structure of reinforced fabric and optimized the coefficient of permeability with minium resin impregnation time. Variable parameters to determine the structure of reinforced fabric and the coefficient of permeability are presented in the table 4.

Table 4. Variable parameters for optimizing the structure of reinforced fabric and the coefficient of permeability

\begin{tabular}{|c|c|c|c|}
\hline Varients & Fabric types & Porosity & $\begin{array}{c}\text { Coefficient of } \\
\text { permeability, } \mathrm{m}^{2}\end{array}$ \\
\hline 1 & Plain & 0.4 & $1.5 \times 10^{-08}$ \\
\hline 2 & Plain & 0.4 & $1.5 \times 10^{-09}$ \\
\hline 3 & Plain & 0.4 & $1.5 \times 10^{-010}$ \\
\hline 4 & Twill (2/1) & 0.42 & $1.5 \times 10^{-08}$ \\
\hline 5 & Twill (2/1) & 0.42 & $1.5 \times 10^{-09}$ \\
\hline 6 & Twill (2/1) & 0.42 & $1.5 \times 10^{-010}$ \\
\hline 7 & Satin (3/1) & 0.48 & $1.5 \times 10^{-08}$ \\
\hline 8 & Satin (3/1) & 0.48 & $1.5 \times 10^{-09}$ \\
\hline 9 & Satin (3/1) & 0.48 & $1.5 \times 10^{-010}$ \\
\hline
\end{tabular}

After the settlement processes were completed, 9 options for modeling calculations were obtained. Of these options, 1 option were selected based on the minium resin impregnation time. The simulation were carried out in the PAM-RTM program to determine the resin impregnation time. As a result of the simulation, the following results were obtained for the samples, which are shown in figure 5,6,7 and table 5. As a results of modeling calculations, the structure of reinforced fabric with minium resin impregnation time was chosen, option was chosen.

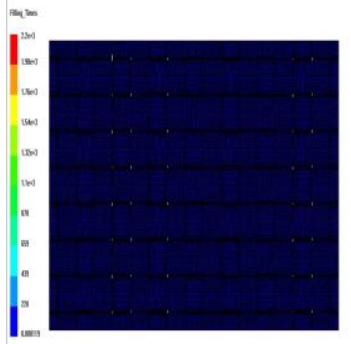

(a)

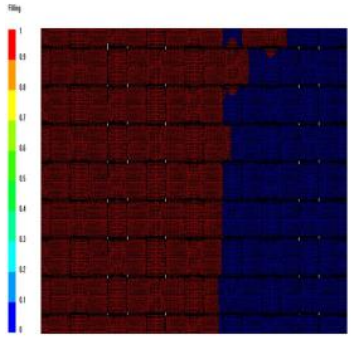

(b)

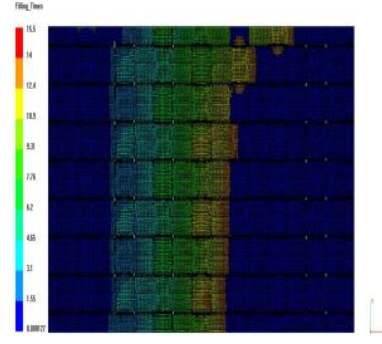

(c)

Fig. 5. Modeling resuts of resin impregnation time for plain weave in the program PAM-RTM : a) with permeability value of $1.5 \times 10^{-08} ; \mathrm{b}$ ) with permeability value of $1.5 \times 10^{-09}$; c) with permeability value of $1.5 \times 10^{-010}$

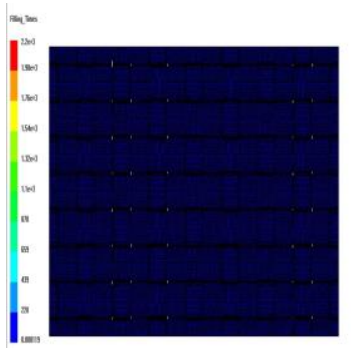

(a)

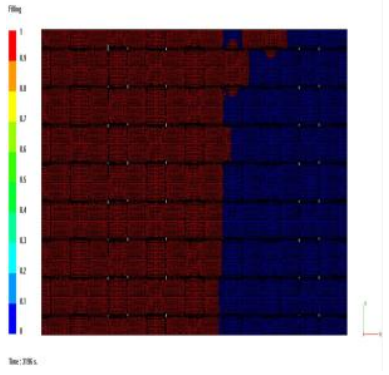

(b)

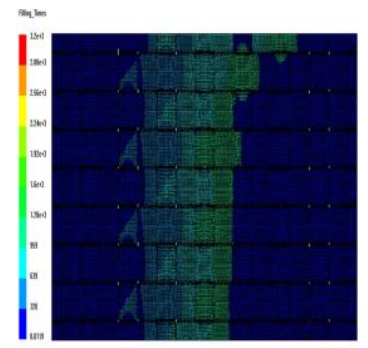

(c)

Fig. 6. Modeling resuts of resin impregnation time for twill weave in the program PAM-RTM : a) with permeability value of $1.5 \times 10^{-08} ; \mathrm{b}$ ) with permeability value of $1.5 \times 10^{-09}$; c) with permeability value of $1.5 \times 10^{-010}$ 


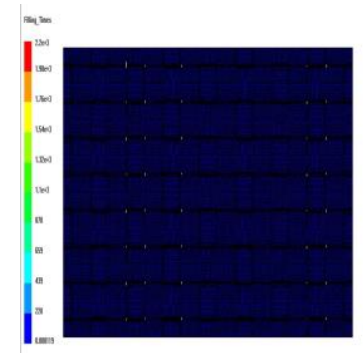

(a)

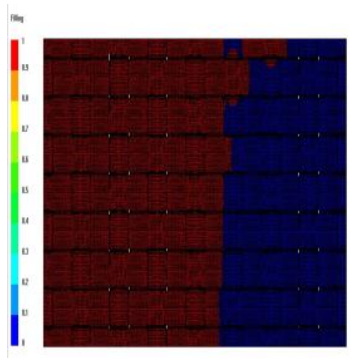

(b)

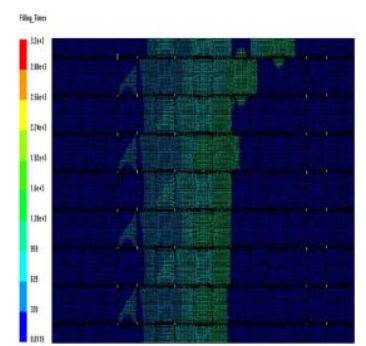

(c)

Fig. 7. Modeling resuts of resin impregnation time for satin weave in the program PAM-RTM : a) with permeability value of $1.5 \times 10^{-08}$; b) with permeability value of $1.5 \times 10^{-09} ; \mathrm{c}$ ) with permeability value of $1.5 \times 10^{-010}$

After the optimization was completed, 210 styling scheme variants were obtained. Their these options are chosen the best options with the limitation of bending and tension. The optimal styling is chosen using the Pareto method to determine the shortest distance from the best options under consideration to the ideal centre (Figure 4).

Table 5. Results of the modeling calculation

\begin{tabular}{|c|c|c|c|c|}
\hline Varients & Fabric types & Porosity & $\begin{array}{c}\text { Coefficient of } \\
\text { permeability, } \mathrm{m}^{2}\end{array}$ & $\begin{array}{c}\text { Resin impregnation } \\
\text { time (sec) }\end{array}$ \\
\hline 1 & Plain & 0.4 & $1.5 \times 10^{-08}$ & 2200 \\
\hline 2 & Plain & 0.4 & $1.5 \times 10^{-09}$ & 2361 \\
\hline 3 & Plain & 0.4 & $1.5 \times 10^{-010}$ & 3196 \\
\hline 4 & Twill (2/1) & 0.42 & $1.5 \times 10^{-08}$ & 1560 \\
\hline 5 & Twill (2/1) & 0.42 & $1.5 \times 10^{-09}$ & 1605 \\
\hline 6 & Twill (2/1) & 0.42 & $1.5 \times 10^{-010}$ & 1719 \\
\hline 7 & Satin (3/1) & 0.48 & $1.5 \times 10^{-08}$ & 1800 \\
\hline 8 & Satin (3/1) & 0.48 & $1.5 \times 10^{-09}$ & 1933 \\
\hline 9 & Satin (3/1) & 0.48 & $1.5 \times 10^{-010}$ & 2174 \\
\hline
\end{tabular}

\section{Conclusions}

This study concludes with the following conclusions:

- Calculations of the selecting of the optimal structure of the composite fabric using epoxy resin (EDT-10) based on different values of permeability are carried out.

- The influence of the permeability of the composite fabric in the manufacture of a composite product is determined.

- The optimal structure of the composite fabric based on the minium resin impregnation time is revealed.

\section{References}

1. Baurova N.I., Zorin V.A., Prikhodko V.M. Determination of the synergetic effect of the damage accumulation process in polymer materials using catastrophe theory. Theoretical Foundations of Chemical Engineering. v.50. №1. pp.119-125. (2016).

2. Baurova N.I., Zorin V.A., Prikhodko V.M. Accuracy of diagnosis of metal structures using carbon fibers // Fibre Chemistry. 2017. v.48. №6. pp.504-506. 
3. Kosenko E.A., Baurova N.I., Zorin V.A. Service properties of composites with various types of hybrid matrices. Russian Metallurgy (Metally). №13. pp. 1526-1530. (2020).

4. Baurova N., Anoprienko A., Romanova Y. Providing dismountable rivet bonded joints through the use of hot-melt joints through the use of hot-melt adhesives. ICMTMTE. v. 129. (2017).

5. Baurova N.I., Makarov K.A. Machining of machine elements made of polymer composite materials. Russion Metallurgy. № 13. pp.1141-1144. (2017).

6. Konoplin A.Yu., Baurova N.I. Hardness of the near-weld zone during contact spot welding of steels using an adhesive-weld technology. Russion Metallurgy. № 13. P.1308-1311. (2016).

7. Malysheva G.V., Shablygin M.V., Guzeva T.A. Method for assessing aramide fiber microstructure feature. Fibre Chemistry. v. 47, №2. P.85-88. (2015).

8. Malysheva G.V., Kirsanova E.A., Mauang P.P., Tumasova M.S. Rigidity of glass carbon and organic yarns of special-purpose fabrics. Fibre Chemistry. v.48, № 2. pp. 140-142. (2016).

9. Gorodetskii M.A., Nelyub V.A., Malysheva G.V., Shaulov A.Y., Berlin A.A. Technology of forming and the properties of reinforced composites based on an inorganic binder. Russian Metallurgy, v. 13. pp.1195-1198. (2018).

10. Nelyub V.A. Technologies of metallization of carbon fabric and the properties of the related carbon fiber reinforced plastics. Russion Metallurgy. № 13. pp.1199-1201. (2018).

11. Nelyub V.A., Tarasov V.A. Ion-beam processing of metallized carbon fiberreinforced plastics. Materials and Manufacturing processes. v.35. №2. pp.172-178. (2020).

12. Baurova N.I., Zorin V.A., Prikhodko V.M. Influence of structural defects in carbon fibers on their sensor properties evaluated using scanning electron microscopy. Fibre Chemistry. v.46. №5. pp.283-287. (2015).

13. Rudskoi A.I., Baurova N.I. Technological heredity during the production and operation of structural materials. Russian Metallurgy, v. 13. pp. 1378-1383. (2019).

14. Baurova N.I., Zorin V.A. Technological heredity in the production of machines from polymer composite materials: monograph. - M. MADI. 220 p. (2018). 